\title{
Hyaluronan-induced masking of ErbB2 and CD44-enhanced trastuzumab internalization in trastuzumab resistant breast cancer
}

Zsuzsanna Pályi-Krekk ${ }^{1}$, Márk Barok ${ }^{1}$, Jorma Isola ${ }^{4}$, Markku Tammi ${ }^{3}$, János Szöllősi ${ }^{1,2}$, Peter $\operatorname{Nagy}^{1 *}$

${ }^{1}$ Department of Biophysics and Cell Biology, ${ }^{2}$ Cell Biophysics Research Group of the Hungarian Academy of Sciences, University of Debrecen, 1 Egyetem sqr, H-4010 Debrecen, Hungary

${ }^{3}$ Department of Anatomy, University of Kuopio, 70211 Kuopio, Finland ${ }^{4}$ Institute of Medical Technology, University and University Hospital of Tampere, 33520 Tampere, Finland

Running title: Masking of ErbB2 by hyaluronan

Keywords: ErbB2, trastuzumab resistance, CD44, hyaluronan, masking

*Corresponding author: Department of Biophysics and Cell Biology, Medical and Health Science Center, University of Debrecen, 1 Egyetem square, H-4010 Debrecen, Hungary. Tel.: +36-52-412623, fax: +36-52-532201, email: nagyp@dote.hu 


\begin{abstract}
Although trastuzumab, a recombinant humanized anti-ErbB2 antibody, is widely used in the treatment of breast cancer, neither its mechanism of action, nor the factors leading to resistance are fully understood. We have previously shown that antibody-dependent cellular cytotoxicity is pivotal in the in vivo effect of trastuzumab against JIMT-1, a cell line showing in vitro resistance to the antibody, and suggested that masking of the trastuzumab-binding epitope by MUC-4, a cell surface mucin, took place. Here, we further explored the role of masking of ErbB2 in connection with CD44 expression and synthesis of its ligand, hyaluronan. We show that high expression of CD44 observed in JIMT-1 cells correlates with ErbB2 downregulation in vivo, while siRNA-mediated inhibition of CD44 expression leads to decreased rate of trastuzumab internalization and low cell proliferation in vitro. An inhibitor of hyaluronan synthesis, 4-methylumbelliferon (4-MU) significantly reduced the hyaluronan level of JIMT-1 cells both in vivo and in vitro leading to enhanced binding of trastuzumab to ErbB2 and increased ErbB2 down-regulation. Furthermore, the inhibitory effect of trastuzumab on the growth of JIMT-1 xenografts was significantly increased by 4-MU treatment. Our results point to the importance of the CD44-hyaluronan pathway in the escape of tumour cells from receptor-oriented therapy.
\end{abstract}




\section{Introduction}

Overexpression of ErbB2 has been unquestionably linked to adverse prognosis in breast cancer. ${ }^{1}$ ErbB2 heterodimerizes with other members of the ErbB family of receptor tyrosine kinases (RTK) leading to enhanced ligand binding affinity, protection from lysosomal degradation and diversified signaling. ${ }^{2}$ ErbB2 is viewed as an non-autonomous, ligand-less, positive regulator of ErbB signaling, ${ }^{2}$ but its participation in non-ErbB protein-mediated signaling is attracting more and more interest as well. Among these, $\beta$-integrins, ${ }^{3} \mathrm{MUC}-4^{4}$ and $\mathrm{CD} 44^{5}$ are probably the best known candidates whose roles in cancer progression are well documented. ${ }^{3,6,7}$ ErbB2 is embedded into this network of signaling and accessory molecules and by its promiscuous association profile it promotes cancer progression. ${ }^{8}$ CD44 is recognized as the major hyaluronan receptor having several, alternatively spliced isoforms varying in their physiological function. ${ }^{9}$ Binding of hyaluronan activates CD44mediated signal transduction pathways via interactions between CD44, Grb2, Vav2 and ErbB2 ${ }^{10} \mathrm{CD} 44$ is involved in the direct regulation of ErbB2 ${ }^{11}$ and multiple other RTKs. ${ }^{12}$ It has been suggested that ligation of CD44 by endogenous hyaluronan leads to the activation of the phosphatidylinositol 3-kinase (PI3K)-Akt survival pathway, ${ }^{13}$ and that displacement of endogenous hyaluronan by exogenous hyaluronan oligosaccharides disrupts the activation. ${ }^{12}$ CD44-mediated cytoskeletal rearrangements have been observed ${ }^{6}$ implying the involvement of CD44 in cellular adhesion, migration and invasion. ${ }^{14} \mathrm{CD} 44$ is almost absent in normal human breast epithelial cells, emerges in benign and premalignant lesions, and is upregulated in carcinomas. ${ }^{15}$ However, a recent study suggested that CD44 opposes rather than promotes the spreading of breast carcinoma in mice. ${ }^{16}$

While the role of CD44 in breast cancer progression in vivo is not completely settled, the accumulation of hyaluronan around malignant cells or in adjacent stroma has been unambiguously shown to be an indicator of poor prognosis in breast cancer. ${ }^{17}$ In line with the findings on human tumours, hyaluronan synthesis facilitates the invasive growth of grafted tumour cells in vivo, ${ }^{18}$ and blocking hyaluronan interactions with its receptors, using soluble CD44 or hyaluronan oligomers, inhibits tumour cell growth in experimental animals. ${ }^{19}$ Besides creating signals to prevent apoptosis ${ }^{13}$, hyaluronan is required for activation of the ErbB2-ErbB3 receptor leading to the formation of cardiac valves. ${ }^{20}$ Thus, there is mounting evidence that ErbB2, CD44 and hyaluronan are connected both in physiological signaling as well as cancer pathogenesis through mechanisms largely unknown at present. ${ }^{5,11}$ 
Being a membrane protein and a key member of survival and proliferation signaling pathways ErbB2 is the target of receptor-oriented antibody therapy. ${ }^{21}$ Trastuzumab (Herceptin), a humanized monoclonal anti-ErbB2 antibody, induces objective clinical responses in $40 \%$ of patients as a single agent given as first-line treatment of ErbB2overexpressing metastatic breast cancer. ${ }^{22}$ Although combination of trastuzumab with conventional chemotherapy increases response rates dramatically, the development of resistance seems currently inevitable. ${ }^{23}$ Direct action of trastuzumab on ErbB2 (e.g. ErbB2 down-regulation, inactivation of Akt, inhibition of metalloprotease-mediated shedding $)^{24}$ and antibody-dependent cellular cytotoxicity (ADCC) $)^{25,26}$ have been invoked to explain the mechanism of action of trastuzumab. Despite intense investigations trastuzumab resistance remains enigmatic and unpredictable in the clinical setting. Production of EGF-like growth factors,${ }^{27}$ loss of PTEN, ${ }^{28}$ masking of ErbB2 ${ }^{4}$ and impaired ADCC reaction ${ }^{29}$ have all been suggested as possible mechanisms.

In the current paper we investigated JIMT-1, a cell line showing in vitro resistance to trastuzumab, ${ }^{30}$ and found a high level of CD44 overexpression. We showed previously that the in vivo trastuzumab resistance of the cell line is partial, and development of complete trastuzumab resistance takes 5-10 weeks. ${ }^{26}$ We suggested that masking of ErbB2 may be the culprit. ${ }^{4}$ Given the suggested association of CD44 with ErbB2 ${ }^{11}$ we asked whether CD44 plays any significant role in the survival of JIMT-1 during trastuzumab therapy. Using siRNA-mediated suppression of CD44 expression we showed that CD44 is necessary for trastuzumab-induced internalization of ErbB2 and for the survival of JIMT-1 cells in vitro. 4methylumbelliferone (4-MU), a hyaluronan synthase inhibitor, has been shown to increase the efficiency of chemotherapy. ${ }^{31}$ We reasoned that hyaluronan may play a role in masking of cell surface ErbB2. ${ }^{32}$ We show that in vitro and in vivo treatment with 4-MU decreased the pericellular hyaluronan concentration in JIMT-1 xenografts accompanied by increased binding of trastuzumab to ErbB2. 4-MU acted synergistically with trastuzumab in inhibiting the progression of JIMT-1 tumours. Elucidation of the role of CD44 overexpression in trastuzumab resistant cell lines may help understand the causes of therapeutic failures in patients with this type of breast cancer. 


\section{Materials and Methods}

Cells. JIMT-1 cells were grown in F-12/ DMEM (1:1) supplemented with 10\% FCS, 60 units/L insulin and antibiotics. ${ }^{30}$ The SKBR-3 cell line was obtained from the American Type Culture Collection (Rockville, MD) and grown according to its specifications.

Antibodies. Trastuzumab (Herceptin) was purchased from Roche Ltd. (Budapest, Hungary). Mab 2C4 was a generous gift from Genentech (South San Francisco, CA). Monoclonal antibodies against ErbB2 (ErbB2-76.5) and CD44 (Hermes-3) were produced from their hybridoma supernatants (ErbB2-76.5 obtained from Y. Yarden, Weizmann Institute of Science, Rehovot, Israel; Hermes-3 produced by the HB-9480 hybrodima obtained from ATCC) and purified using protein A affinity chromatography. Hermes-3 was kindly donated by Dr. Sirpa Jalkanen (University of Turku, Finland). Cy3- and Cy5-conjugated goat anti human IgG $(\mathrm{H}+\mathrm{L})$ Fab was obtained from Jackson ImmunoResearch Europe (Cambridgeshire, UK). Conjugation of primary antibodies with AlexaFluor (Molecular Probes, Eugene, OR), Cy3 and Cy5 (Amersham, Braunschweig, Germany) dyes was carried out according to the manufacturers' specifications.

Hyaluronan. Highly purified large molecular weight hyaluronan (HA-LMW) with an average molecular mass of $1.2 \times 10^{6}$ Da was donated by Genzyme (Cambridge, MA). Purified hyaluronan decasaccharides (HA10) were kindly provided by Seikagaku Corporation (Tokio, Japan).

Western blotting. Whole cell lysates were prepared in lysis buffer containing $20 \mathrm{mM}$ Tris$\mathrm{HCl}, \mathrm{pH}$ 7.5, $150 \mathrm{mM} \mathrm{NaCl}, 10 \%$ glycerol, 1 mM EGTA, $1 \%$ Triton X-100, 1 Complete Mini (Roche, Mannheim, Germany) protease inhibitor cocktail tablet/10 mL, $1 \mathrm{mM} \mathrm{Na} \mathrm{VO}_{4}$, $1 \mathrm{mM}$ PMSF, $10 \mathrm{mM} \mathrm{NaF}, 10 \mathrm{mM} \beta$-glycerol phosphate and $10 \mathrm{mM} \mathrm{Na}_{4} \mathrm{P}_{2} \mathrm{O}_{7}$. Immunoprecipitation of ErbB2 and ErbB1 were carried out with Ab3-OP15 antibody (Calbiochem-Merck Biosciences, Schwalbach, Germany) and F4 (E3138, Sigma, Schnelldorf, Germany), respectively, for $1 \mathrm{~h}$ on ice and Sepharose 4B Fast Flow Protein G beads (Sigma). Immunoprecipitates were resolved on SDS-polyacrylamide gels and blotted to nitrocellulose membranes. The following antibodies were used for primary labelling of the membranes at dilutions suggested by the manufacturers: Ab3-OP15 for ErbB2, F4 for ErbB1, PY99-sc7020 (Santa Cruz Biotechnology, Santa Cruz, CA) for phosphotyrosine and Hermes- 
3 for CD44. Peroxidase-conjugated goat anti-mouse IgG and an enhanced

chemiluminescence kit (Amersham, Freiburg, Germany) were used for detection.

Flow cytometric measurement of cell numbers and receptor expression levels.

Quantitative determination of receptor expression levels was carried out on a FACSCalibur flow cytometer (Becton Dickinson, Franklin Lakes, NJ) using Qifikit (DakoCytomation, Glostrup, Denmark) according to the manufacturer's instructions. In proliferation assays cells were counted with a FacsArray flow cytometer (Becton Dickinson).

Xenograft tumours. The severe combined immunodeficiency (SCID) C.B-17 scid/scid mouse population originated from the laboratory of Fox Chase Cancer Center, Philadelphia, PA, and were housed in a pathogen-free environment. Only nonleaky mice with murine IgG levels below $100 \mathrm{ng} / \mathrm{ml}$ were used in this study. Seven-week old female SCID mice were given a single subcutaneous injection of $5 \times 10^{6}$ JIMT-1 cells suspended in $150 \mu$ l Hank's buffer and mixed with an equal volume of Matrigel (Basement Membrane Matrigel, BD Biosciences, Bedford, MA). Tumour volumes were calculated as the product of the length, width and height of the tumour measured once a week with a caliper. Trastuzumab was administered at a dose of $5 \mu \mathrm{g} / \mathrm{g}$ by weekly intraperitoneal (i.p.) injection. Control mice received weekly i.p. injection of $100 \mu$ physiologic saline. Animals were euthanized by $\mathrm{CO}_{2}$ inhalation. The experiments were done with the approval of the ethical committee of the University of Debrecen.

4-methylumbelliferone treatment. 4-methylumbelliferone (4-MU) (Sigma, Budapest, Hungary), an inhibitor of hyaluronan synthase, was suspended in $1 \%$ arabic gum and administered orally at a dose of $3 \mathrm{mg} / \mathrm{g}$ body weight twice daily. ${ }^{33}$ For in vitro experiments 4MU was dissolved in PBS and added to the culture medium at a concentration of $1 \mathrm{mM}$. Immunohistochemistry. Subcutaneous tumours were removed from anesthetized mice, covered with Shandon Cryomatrix (Thermo Electron Corporation, Waltham, MA) and stored in liquid nitrogen. $20-\mu \mathrm{m}$ thick fast frozen samples were made by Shandon AS-620E Cryotome (Thermo Electron Corporation) on silanized slides, fixed in $4 \%$ formaldehyde for 30 min, and washed twice in PBS (pH 7.4) supplemented with 1\% BSA for 20 min at room temperature. The slides were labeled with a saturating concentration $(10-20 \mu \mathrm{g} / \mathrm{ml})$ of fluorophore-conjugated antibodies in $100 \mu \mathrm{PBS}$ containing 1\% BSA (PBS-BSA) overnight on ice. The samples were washed twice with PBS-BSA and covered with $15 \mu 1$ Mowiol (Merck, Budapest, Hungary). For labelling of hyaluronan tissue sections were treated with endogenous biotin blocking kit (Molecular Probes) followed by labelling with $5 \mu \mathrm{g} / \mathrm{ml}$ 
biotinylated HABC (hyaluronan binding complex) at $4{ }^{\circ} \mathrm{C}$ overnight. ${ }^{34}$ Prior to staining with fluorescein-avidin the samples were washed five times in PBS-BSA.

Confocal microscopy. A Zeiss LSM 510 confocal laser-scanning microscope (Carl Zeiss AG, Göttingen, Germany) was used to image samples. AlexaFluor488 was excited at $488 \mathrm{~nm}$ and detected between $505-530 \mathrm{~nm}$. Cy3 and AlexaFluor546 were excited with the $543 \mathrm{~nm}$ line of a green He-Ne laser, and emission was measured between 560-615 nm. Cy5 and AlexaFluor647 were excited with the $633 \mathrm{~nm}$ line of a red He-Ne laser, and their emissions were measured over $650 \mathrm{~nm}$. Fluorescence images were taken as $1-\mu \mathrm{m}$ optical sections using a $63 \mathrm{x}(\mathrm{NA}=1.4)$ oil immersion objective.

Image analysis. Confocal microscopic images were analyzed with the DipImage toolbox (Delft University of Technology, Delft, The Netherlands) under Matlab (Mathworks Inc., Natick, MA). The cell membrane was identified by a manually-seeded watershed algorithm ${ }^{35}$ using a customwritten interactive algorithm implemented in Dipimage/Matlab. The fluorescence intensity was evaluated only in pixels corresponding to the cell membrane. For the analysis of the influence of CD44 expression on the relative binding of trastuzumab to ErbB2 tissue sections were triplelabeled with AlexaFluor488-ErbB2-76.5, Cy3-anti-human IgG (to visualize trastuzumab) and AlexaFluor647-Hermes-3 (against CD44). A two-dimensional histogram (dot plot) of trastuzumab vs. ErbB2 intensity was prepared using only membrane pixels. The CD44 expression level was separately evaluated in pixels corresponding to high trastuzumab/ErbB2 and low trastuzumab/ErbB2 ratios identified based on the dot plot.

Colocalization between two different fluorescent labels was calculated according to Pearson's formula:

$$
\frac{\sum_{k}\left(I_{k}-I_{\text {mean }}\right)\left(J_{k}-J_{\text {mean }}\right)}{\sqrt{\sum_{k}\left(I_{k}-I_{\text {mean }}\right)^{2} \sum_{k}\left(J_{k}-J_{\text {mean }}\right)^{2}}}
$$

where $I_{k}$ and $J_{k}$ are the intensities of the $\mathrm{k}^{\text {th }}$ pixel in the first and second image, respectively, $I_{\text {mean }}$ and $J_{\text {mean }}$ are the average fluorescence intensities of the first and second image, respectively. Low intensity pixels were excluded from the analysis. The value of the crosscorrelation coefficient ranges from +1 to -1 . Values close to 1, 0 and -1 indicate high and low degree of colocalization, and anticorrelation, respectively. Colocalization was evaluated using a custom-made software written in LabView (National Instruments, Austin, TX).

Fluorescence resonance energy transfer (FRET). Flow cytometric FRET measurements were performed on a FACSVantage SE instrument with DiVa option (Becton Dickinson) 
equipped with three lasers emitting at 488, 532 and $633 \mathrm{~nm}$. A detailed description of the method has been published elsewhere. ${ }^{36}$ Cellular autofluorescence was measured in the FL1 channel (excited by the $488 \mathrm{~nm}$ laser) through a 530/30 $\mathrm{nm}$ band pass filter to discard debris and dead cells. Donor fluorescence was excited at $532 \mathrm{~nm}$ and recorded in the FL4 channel through a 585/42 $\mathrm{nm}$ bandpass filter, while the acceptor was excited at $633 \mathrm{~nm}$ and detected in the FL6 channel through a $650 \mathrm{~nm}$ long pass filter. The FRET intensity was excited at 532 $\mathrm{nm}$ and detected in the FL5 channel through a $650 \mathrm{~nm}$ long pass filter. Calculations were carried out on a cell-by-cell basis using the ReFlex software. ${ }^{37}$ FRET efficiencies were normalized to a 1:1 donor-acceptor ratio ${ }^{38}$ and are presented as mean values of FRET histograms of 10,000 cells.

Internalization of trastuzumab. siRNA-transfected and control cells were incubated with 20 $\mu \mathrm{g} / \mathrm{ml}$ AlexaFluor647-labeled trastuzumab at $37^{\circ} \mathrm{C}$. The samples were treated with acid strip buffer ( $0.5 \mathrm{M} \mathrm{NaCl}, 0.1 \mathrm{M}$ glycine, $\mathrm{pH} 2.5)$ for 3 minutes on ice followed by washing and resuspension in PBS. Cells were analyzed by flow cytometry, and the internalized fraction of trastuzumab was calculated by dividing the mean fluorescence intensity of the acid-stripped sample with that of the non-acid-treated control.

RNA interference (RNAi). Small interfering RNA (siRNA) against human CD44 were designed and synthesized by Dharmacon (Chicago, IL) using the SMARTselection rules. The sequences of the anti-sense strands of the siRNAs are: AUGUCUUCAGGAUUCGUUCUU (CD44 siRNA-4), UAUUCAAAUCGAUCUG CGCUU (CD44 siRNA-5). An siRNA against GFP was used as a negative control. ${ }^{39}$ siRNA transfection of JIMT-1 was carried out with the Nucleofector device of Amaxa (Cologne, Germany) according to the manufacturer's specifications. The optimal electroporation conditions (solution V, program T-20) were selected using GFP plasmid transfection. 


\section{Results}

\section{CD44 is overexpressed on trastuzumab resistant JIMT-1 cells and associated with}

ErbB2. We compared the expression levels of CD44 in trastuzumab resistant and sensitive breast cancer cell lines in order to reveal the possible roles of CD44 in trastuzumab resistance. Flow cytometric data showed a $\sim 35$-times higher expression level of CD44 in trastuzumab resistant JIMT-1 cells (2.3 \pm 0.3 million/cell) than in SKBR-3 (65000 $\pm 5000 /$ cell), their trastuzumab-sensitive counterpart (Fig.1A). Since CD44 has been shown to interact with ErbB2 in ovarian cancer, ${ }^{5,10}$ we investigated the potential interaction between them. Analysis of confocal microscopic images yielded cross-correlation coefficients of 0.612 and 0.602 between CD44 and ErbB2 on JIMT-1 and SKBR-3 cells, respectively (Fig.1B,C). The crosscorrelation coefficient between two different antibodies against ErbB2 was used as a positive control. The fact that the cross-correlation coefficient of the positive control was not substantially different from that between CD44 and ErbB2 implies a strong colocalization between these molecules on the micrometer scale. Normalized flow cytometric fluorescence resonance energy transfer (FRET) values of $16 \pm 3 \%$ and $10 \pm 3 \%$ for the association of CD44 and ErbB2 in JIMT-1 and SKBR-3, respectively, show that these molecules are associated at the molecular level as well (Fig.1B), since FRET values above 5\% are considered to imply significant association. ${ }^{40}$ The above biophysical data demonstrating association between ErbB2 and CD44 in JIMT-1 cells were reinforced by molecular biological methods. ErbB2 co-immunoprecipitated with CD44 (Fig. 1D, left panel), and its tyrosine phosphorylation was increased by large molecular weight hyaluronan, whereas hyaluronan decasaccharide inhibited ErbB2 tyrosine phosphorylation (Fig. 1D, middle panel). Neither slow, nor large molecular weight hyaluronan modified the activation state of ErbB1 (Fig. 1D, right panel). CD44 expression correlates with trastuzumab internalization in JIMT-1 xenografts. In order to study the possible role of CD44 overexpression in trastuzumab resistance sevenweek old female SCID mice were inoculated by JIMT-1 cells with a single subcutaneous injection. Mice received trastuzumab or physiologic saline weekly starting immediately after tumour injection. Mice were treated with trastuzumab for 9 weeks, then by physiologic saline for another 6 weeks before sacrificing. Tumour sections were triple-stained against ErbB2, trastuzumab and CD44. The watershed algorithm was used to segment the images. The seeds for the watershed algorithm were placed inside cells positive for CD44 and ErbB2. Since mouse stromal cells express neither CD44 nor ErbB2, this approach ensured that the analysis was restricted to JIMT-1 cells. We observed a lack of tight correlation between trastuzumab binding and ErbB2 expression in these mice whose trastuzumab therapy had 
been suspended for 6 weeks (Fig. 2B,D). The trastuzumab/ErbB2 ratio was inversely correlated with CD44 expression, i.e. cells in which the relative binding of trastuzumab to ErbB2 was low displayed high CD44 expression (Fig. 2D,E). The lack of strict correlation between trastuzumab binding and ErbB2 expression could be caused by local heterogeneities in trastuzumab binding or internalization. We excluded the role of trastuzumab binding by investigating tumour sections from mice sacrificed immediately after 15 weeks of trastuzumab treatment and showing a tight correlation between trastuzumab binding and ErbB2 expression (Fig. 2F). Unfortunately, direct quantitation of trastuzumab internalization by measuring fluorescence intensity inside cells was not possible due to the low signal-tonoise ratio. Therefore, we used an alternative approach by analyzing the correlation between CD44 and ErbB2 expressions before, during and after trastuzumab treatment, and found that they show a positive correlation in control mice (Fig. 2G) and in mice in which trastuzumab treatment has been stopped (Fig. 2I). Strikingly, CD44 and ErbB2 expression levels were inversely correlated with each other during trastuzumab treatment (Fig. 2H), i.e. pixels with high CD44 expression displayed low ErbB2 intensity and vica versa. This finding can be rationalized by assuming that ErbB2 is internalized and down-regulated more efficiently in cells with high CD44 expression.

\section{RNA interference (RNAi)-mediated suppression of CD44 expression inhibits}

trastuzumab internalization. The in vivo results supporting the role of CD44 in trastuzumab-mediated ErbB2 internalization were tested by in vitro RNAi experiments. Two siRNAs against CD44 elicited efficient and specific inhibition of CD44 expression in JIMT-1 supported by the lack of effect of an irrelevant siRNA on CD44 expression, and the lack of CD44 siRNA-induced suppression of the expression of an irrelevant protein (Fig. 3A).

Quantitative flow cytometric analysis confirmed that CD44 siRNAs inhibited trastuzumab internalization by $\sim 50 \%$ (Fig. 3B).

\section{4-methylumbelliferone (4-MU) synergizes with trastuzumab in inhibiting the growth of}

JIMT-1 xenografts. We showed that CD44 plays a role in trastuzumab internalization both in vivo and in vitro. However, the contribution of trastuzumab-mediated ErbB2 internalization to the mechanism of action of the antibody has been repeatedly questioned 41,42. Therefore, we directly tested whether the CD44-hyaluronan pathway can influence the therapeutic efficacy of trastuzumab. Mice injected with JIMT-1 xenografts were treated with 4-MU (an inhibitor of hyaluronan synthase ${ }^{33}$ ) or trastuzumab, or both starting immediately after tumour inoculation. Each treatment group contained eight animals. The fact that trastuzumab treatment was started the same day as tumour injection made JIMT-1 cells 
(showing in vitro trastuzumab resistance) responsive to the treatment. ${ }^{26} 4-\mathrm{MU}$ combined with trastuzumab was significantly more effective in inhibiting the growth of JIMT-1 xenografts than trastuzumab alone (Fig. 4A). 4-MU did not have any effect on tumour growth on its own (Fig. 4A), although it reduced the amount of hyaluronan in JIMT-1 tumour tissue by $\sim 40 \%$ (Fig. 4B). In addition, CD44 expression was increased by 4-MU probably due to its decreased hyaluronan-mediated down-regulation. ${ }^{43}$ The increased CD44 level of trastuzumab-treated cells is probably the consequence of reduced CD44 shedding in the presence of trastuzumab (our unpublished observation). 4-MU downregulated ErbB2 to the same extent as trastuzumab. We attribute this finding to the fact that 4-MU increased the CD44 level of cells which was shown to correlate with increased ErbB2 internalization

(Fig. 2). Not only did 4-MU synergize with trastuzumab in slowing tumour growth, but it also enhanced trastuzumab-mediated down-regulation of ErbB2 (Fig. 4B). Since we assumed that 4-MU may unmask the trastuzumab-binding epitope on ErbB2, it was necessary to show that hyaluronan colocalized with the plasma membrane. By staining tumour sections for hyaluronan and CD44 we demonstrated that hyaluronan is present near the cell membrane, although it is also found in high density in areas which seem to be interstitial tissue (Fig. 5AC). Next, we determined the trastuzumab/ErbB2 ratio in control and trastuzumab+4-MUtreated tumour samples and observed an obvious increase in the relative binding of trastuzumab to ErbB2 upon 4-MU treatment (Fig. 5D-E). Quantitative analysis of the images showed a shift on the trastuzumab-ErbB2 contour plot towards higher trastuzumab binding upon 4-MU treatment (Fig. 5F). Next, we tested the effect of in vitro 4-MU treatment on trastuzumab binding. JIMT-1 cells were treated with 4-MU for 48 hours, and subsequently labeled with AlexaFluor488-trastuzumab and AlexaFluor647-2C4. We found that 4-MU treatment enhanced the amount of bound trastuzumab relative to the intensity of ErbB2 (Fig. $5 G)$. ErbB2 was not downregulated by trastuzumab in Fig. 5G, since cells were labeled with trastuzumab for $30 \mathrm{~min}$ on ice, as opposed to Fig. 5F, where mice were treated with the antibody for several weeks. The trastuzumab epitope is masking sensitive ${ }^{4}$ due to its membrane proximal position. ${ }^{44}$ Since the ErbB2-76.5 and $2 \mathrm{C} 4$ antibodies recognize an epitope distinct from and less masking sensitive than that of trastuzumab (our unpublished observation), we assumed that their intensities represented the total amount of ErbB2. The 4MU-induced changes in the trastuzumab/ErbB2 ratio present convincing evidence for the in vitro and in vivo masking effect of hyaluronan on the trastuzumab binding epitope.

CD44 is essential for the proliferation of JIMT-1 cells in vitro. Since CD44 is overexpressed by JIMT-1 cells and it is involved in regulating trastuzumab-mediated ErbB2 
internalization, we investigated whether the inhibition of CD44 expression alters the effect of trastuzumab in vitro. As previously shown JIMT-1 cells were resistant to trastuzumab in vitro, ${ }^{30}$ but their proliferation was inhibited by siRNA-mediated suppression of CD44 expression (Fig. 6). However, no additive effect between trastuzumab and CD44 siRNA was detected. SKBR-3 cells responded to trastuzumab treatment, but in agreement with their low CD44 expression failed to show any response to siRNA-mediated suppression of CD44 expression (Fig. 6). 


\section{Discussion}

CD44 is widely recognized as a key factor in lymphocyte homing and cancer progression. ${ }^{14}$ It has been shown to enhance the signaling potency of several growth factor receptors in general $^{12}$ and to interact with ErbB2 in particular, ${ }^{5,10,11}$ but the involvement of the hyaluronan-CD44 pathway in trastuzumab resistance has not been investigated. Since the mechanisms behind trastuzumab resistance are largely unknown, therapeutic failure during prolonged treatment is practically inevitable. In JIMT-1, a cell line showing in vitro and partial in vivo resistance to trastuzumab, ${ }^{4,30}$ we found an overexpression of CD44. High expression of CD44 is a property of breast cancer stem cells ${ }^{45}$ raising the possibility that the JIMT-1 cell line has been initiated from a stem/progenitor cell. Immunoprecipitation, flow cytometric FRET and confocal microscopic experiments showed that CD44 associates with ErbB2. The interaction between CD44 and ErbB2 hinted that the hyaluronan-CD44 pathway may be involved in trastuzumab internalization and resistance.

siRNA-mediated suppression of CD44 expression inhibited trastuzumab internalization in vitro (Fig. 3). Since CD44 is known to be linked to actin ${ }^{6}$ and endocytosis and post-endocytic sorting are coupled to the cytoskeleton in several ways ${ }^{46}$, it is possible that inhibition of the expression of CD44 interferes with the endocytic process. Alternatively, since CD44 plays a permissive role in the activation of ErbB2, ${ }^{11}$ elimination of this constitutive regulator of ErbB2 may inhibit trastuzumab internalization. The role of CD44 in trastuzumab internalization and down-regulation was confirmed by studying the correlation between trastuzumab binding, ErbB2 and CD44 expressions in JIMT-1 xenografts. In control mice the correlation between CD44 and ErbB2 expressions was positive (Fig. 2G), which was converted to an inverse correlation by trastuzumab treatment (Fig. 2H). ErbB2 is downregulated by trastuzumab (Fig. 4B), and we assume that this process is more efficient in cells with high CD44 expression, therefore CD44 ${ }^{\text {high }}$ cells will end up being low expressers of ErbB2 upon trastuzumab treatment. The fact that CD44 expression correlates with trastuzumab-induced ErbB2 internalization in vivo agrees with our in vitro data showing decreased internalization of trastuzumab after knocking down CD44 expression (Fig. 3). We showed previously that after stopping trastuzumab injections ErbB2 expression returns to a level observed in untreated animals. ${ }^{26}$ While trastuzumab is cleared from the circulation resynthesis of ErbB2 takes place primarily in cells in which ErbB2 expression was downregulated, i.e. the CD44 ${ }^{\text {high }}$ subpopulation. Trastuzumab will probably not bind to ErbB2 synthesized 6 weeks after stopping trastuzumab treatment, since the antibody is eliminated from the circulation with a half-life of $\sim 25$ days, ${ }^{47}$ and its concentration is probably lower in 
the tumour stroma than in the circulation. Even if trastuzumab had bound to newly synthesized ErbB2 six weeks after stopping trastuzumab treatment, we would not have observed substantial cell-to-cell variation in the binding of trastuzumab to ErbB2 (Fig. 2D). Therefore, CD44 ${ }^{\text {high }}$ cells in which ErbB2 has been down-regulated will display newly synthesized ErbB2 without trastuzumab on their surface, i.e. their trastuzumab/ErbB2 ratio will be lower than that of CD44 ${ }^{\text {low }}$ cells in which ErbB2 has been down-regulated less efficiently (Fig. 2D,E). The trastuzumab/ErbB2 ratio of CD44 ${ }^{\text {low }}$ cells was high because they still displayed ErbB2 in their membrane to which trastuzumab had bound during trastuzumab treatment. Although the role of trastuzumab-induced ErbB2 down-regulation in the therapeutic action of the antibody has been questioned ${ }^{41,42}$, the debate is not yet settled. The finding that CD44 is involved in ErbB2 internalization and down-regulation shows that it influences the distribution of ErbB2 among different cellular compartments, which may alter the therapeutic effects of trastuzumab. Additionally, if trastuzumab is used to target ErbB2 overexpressing cells with radioactive isotopes or chemotherapeutics, entry of the antibodycoupled drug into the cell will be affected by the level of CD44 expression.

In addition to its involvement in regulating endocytosis of ErbB2, CD44 can modify trastuzumab-induced effects by masking ErbB2 by its bulky ligand, hyaluronan. We have previously described masking of ErbB2 by MUC-4, a cell surface mucin, also expressed by the JIMT-1 cell line. ${ }^{4}$ In this paper we established that hyaluronan also masks the trastuzumab binding epitope by showing that hyaluronan was present in the immediate vicinity of JIMT-1 cells (Fig. 5A-C), and 4-MU, an inhibitor of hyaluronan synthase, ${ }^{33}$ substantially reduced its concentration accompanied by increased trastuzumab binding (Fig. 4B, 5F). The enhanced expression level of CD44 in 4-MU-treated xenografts (Fig. 4B) is probably attributable to lower rate of hyaluronan-induced CD44 endocytosis. ${ }^{43}$ Since CD44 seems to increase ErbB2 down-regulation (Fig. 3B), the higher CD44 level in 4-MU-treated samples may lead to the lower level of ErbB2 expression observed in these animals (Fig. 4B). Decreased concentration of hyaluronan around JIMT-1 cells resulted in increased binding of trastuzumab to (Fig. 5D-F) and more efficient down-regulation of ErbB2 (Fig. 4B). More importantly, the enhanced binding of trastuzumab to ErbB2 induced by 4-MU increased the efficiency of trastuzumab therapy in vivo (Fig. 4A). It has been shown previously that hyaluronan-cell interactions are important for cancer cell survival and metastasis. ${ }^{48}$ The fact that 4-MU alone did not alter the rate of JIMT-1 tumour growth compared to saline-treated animals suggests that either hyaluronan is not necessary for the survival of JIMT-1 cells or the extent of suppression of hyaluronan synthesis was not sufficient for evoking an effect on 
tumour growth. Nevertheless, the suppression of hyaluronan synthesis induced by 4-MU treatment was large enough to decrease masking of ErbB2 and increase the binding and therapeutic effect of trastuzumab. It was reported that 4-MU inhibited the proliferation of keratinocytes more strongly than expected based on the level of inhibition of hyaluronan synthesis. ${ }^{49}$ This phenomenon was attributed to direct antiproliferative effects of 4-MU unrelated to hyaluronan synthesis. The fact that 4-MU as a single agent was ineffective in our study argues against this possibility in JIMT-1 cells. Although 4-MU specifically inhibits the synthesis of hyaluronan, ${ }^{33}$ we cannot rule out the possibility that the production of other glycosaminoglycans was also suppressed. However, the observed increase in trastuzumab binding after 4-MU treatment is a solid evidence for masking whatever molecules are behind it.

The extremely high overexpression of CD44 by JIMT-1 cells ( $\sim 2.3$ million/cell) must be maintained by a selective advantage conferred upon cells by CD44. Although the overexpression of ErbB2 is less high (0.1-0.5 million/cell $\left.{ }^{3,4}\right)$ it is probably a key signaling molecule in JIMT-1. Therefore, we wanted to investigate whether the combination of therapies against two overexpressed proteins results in synergism, i.e. whether suppression of CD44 expression will turn trastuzumab resistance into responsiveness. siRNA-mediated knockdown of CD44 expression decreased the proliferation of JIMT-1, but cells remained trastuzumab resistant (Fig. 6). The failure to induce trastuzumab sensitivity in JIMT-1 cells by CD44 siRNA transfection may have been caused by a possible antagonism between CD44 siRNA and trastuzumab, since the former inhibits the internalization of the latter (Fig. 3B). Alternatively, the CD44-hyaluronan pathway involved in in vivo trastuzumab resistance may have very limited role in the in vitro resistance of JIMT- $1{ }^{4}$ It is also possible that although CD44 is involved in trastuzumab internalization, it is unrelated to trastuzumab resistance due to the dubious role of ErbB2 internalization and downregulation in trastuzumab resistance. ${ }^{41}$

In conclusion, our results point to a role of CD44 in regulating trastuzumab internalization and masking ErbB2 by serving as an anchor of the hyaluronan meshwork. These findings warrant further investigation of the correlation between trastuzumab resistance, masking of ErbB2, CD44 and hyaluronan expressions, and a deeper look at how CD44-expressing breast cancer stem cells are affected by trastuzumab therapy. 


\section{Acknowledgements}

We are indebted to Dr. István Juhász for allowing access to the animal care facility of the Department of Dermatology, University of Debrecen, to Dr. Sirpa Jalkanen (University of Turku, Finland) for providing the Hermes-3 antibody and to Gábor Horváth for helping in the FRET measurements. We gratefully acknowledge the excellent technical assistance of Ferenc Bostyán in the animal experiments.

Grant support: Hungarian Academy of Sciences (OTKA F049025, T043061, K62648) and European Commission (LSHB-CT-2004-503467, LSHC-CT-2005-018914) grants to PN, JS; Academy of Finland \# 107173 (MT)

\section{Conflict of interest}

None declared. 


\section{References}

1. Ross JS, Fletcher JA, Linette GP, Stec J, Clark E, Ayers M, Symmans WF, Pusztai L, Bloom KJ. The Her-2/neu gene and protein in breast cancer 2003: biomarker and target of therapy. Oncologist 2003;8:307-325.

2. Citri A, Yarden Y. EGF-ERBB signalling: towards the systems level. Nat Rev Mol Cell Biol 2006;7:505-516.

3. Mocanu MM, Fazekas Z, Petrás M, Nagy P, Sebestyén Z, Isola J, Timar J, Park JW, Vereb G, Szöllősi J. Associations of ErbB2, beta1-integrin and lipid rafts on Herceptin (Trastuzumab) resistant and sensitive tumor cell lines. Cancer Lett 2005;227:201-212.

4. Nagy P, Friedländer E, Tanner M, Kapanen AI, Carraway KL, Isola J, Jovin TM. Decreased accessibility and lack of activation of ErbB2 in JIMT-1, a Herceptin-resistant, MUC4-expressing breast cancer cell line. Cancer Res 2005;65:473-482.

5. Bourguignon LY, Zhu H, Chu A, Iida N, Zhang L, Hung MC. Interaction between the adhesion receptor, CD44, and the oncogene product, p185HER2, promotes human ovarian tumor cell activation. J Biol Chem 1997;272:27913-27918.

6. Bourguignon LY. CD44-mediated oncogenic signaling and cytoskeleton activation during mammary tumor progression. J Mammary Gland Biol Neoplasia 2001;6:287-297.

7. Carraway KL, Ramsauer VP, Carraway CA. Glycoprotein contributions to mammary gland and mammary tumor structure and function: roles of adherens junctions, ErbBs and membrane MUCs. J Cell Biochem 2005;96:914-926.

8. Holbro T, Civenni G, Hynes NE. The ErbB receptors and their role in cancer progression. Exp Cell Res 2003;284:99-110.

9. Naor D, Sionov RV, Ish-Shalom D. CD44: structure, function, and association with the malignant process. Adv Cancer Res 1997;71:241-319.

10. Bourguignon LY, Zhu H, Zhou B, Diedrich F, Singleton PA, Hung MC. Hyaluronan promotes CD44v3-Vav2 interaction with Grb2-p185(HER2) and induces Rac1 and Ras signaling during ovarian tumor cell migration and growth. $J$ Biol Chem 2001;276:48679-48692.

11. Ghatak S, Misra S, Toole BP. Hyaluronan constitutively regulates ErbB2 phosphorylation and signaling complex formation in carcinoma cells. $J$ Biol Chem 2005;280:8875-8883.

12. Misra S, Toole BP, Ghatak S. Hyaluronan constitutively regulates activation of multiple receptor tyrosine kinases in epithelial and carcinoma cells. $J$ Biol Chem 2006;281:34936-34941. 
13. Ghatak S, Misra S, Toole BP. Hyaluronan oligosaccharides inhibit anchorageindependent growth of tumor cells by suppressing the phosphoinositide 3kinase/Akt cell survival pathway. J Biol Chem 2002;277:38013-38020.

14. Marhaba R, Zoller M. CD44 in cancer progression: adhesion, migration and growth regulation. J Mol Histol 2004;35:211-231.

15. Auvinen P, Tammi R, Tammi M, Johansson R, Kosma VM. Expression of CD44s, CD44v3 and CD44v6 in benign and malignant breast lesions: correlation and colocalization with hyaluronan. Histopathology 2005;47:420-428.

16. Lopez JI, Camenisch TD, Stevens MV, Sands BJ, McDonald J, Schroeder JA. CD44 attenuates metastatic invasion during breast cancer progression. Cancer Res 2005;65:6755-6763.

17. Auvinen P, Tammi R, Parkkinen J, Tammi M, Agren U, Johansson R, Hirvikoski P, Eskelinen M, Kosma VM. Hyaluronan in peritumoral stroma and malignant cells associates with breast cancer spreading and predicts survival. Am J Pathol 2000;156:529-536.

18. Simpson MA, Wilson CM, McCarthy JB. Inhibition of prostate tumor cell hyaluronan synthesis impairs subcutaneous growth and vascularization in immunocompromised mice. Am J Pathol 2002;161:849-857.

19. Peterson RM, Yu Q, Stamenkovic I, Toole BP. Perturbation of hyaluronan interactions by soluble CD44 inhibits growth of murine mammary carcinoma cells in ascites. Am J Pathol 2000;156:2159-2167.

20. Camenisch TD, Schroeder JA, Bradley J, Klewer SE, McDonald JA. Heart-valve mesenchyme formation is dependent on hyaluronan-augmented activation of ErbB2-ErbB3 receptors. Nat Med 2002;8:850-855.

21. Slamon DJ, Leyland-Jones B, Shak S, Fuchs H, Paton V, Bajamonde A, Fleming T, Eiermann W, Wolter J, Pegram M, Baselga J, Norton L. Use of chemotherapy plus a monoclonal antibody against HER2 for metastatic breast cancer that overexpresses HER2. N Engl J Med 2001;344:783-792.

22. Tokunaga E, Oki E, Nishida K, Koga T, Egashira A, Morita M, Kakeji Y, Maehara Y. Trastuzumab and breast cancer: developments and current status. Int J Clin Oncol 2006;11:199-208.

23. Cardoso F, Piccart MJ, Durbecq V, Di LA. Resistance to trastuzumab: a necessary evil or a temporary challenge? Clin Breast Cancer 2002;3:247-257.

24. Nahta R, Esteva FJ. Herceptin: mechanisms of action and resistance. Cancer Lett 2006;232:123-138.

25. Clynes RA, Towers TL, Presta LG, Ravetch JV. Inhibitory Fc receptors modulate in vivo cytoxicity against tumor targets. Nat Med 2000;6:443-446.

26. Barok M, Isola J, Pályi-Krekk Z, Nagy P, Juhász I, Vereb G, Kawano Y, Kauraniemi P, Kapanen A, Tanner M, Vereb G, Szöllösi J. Trastuzumab causes ADCC- 
mediated growth inhibition of submacroscopic JIMT-1 breast cancer xenografts despite intrinsic drug resistance. Mol Cancer Ther 2007;6:20652072.

27. Motoyama AB, Hynes NE, Lane HA. The efficacy of ErbB receptor-targeted anticancer therapeutics is influenced by the availability of epidermal growth factor-related peptides. Cancer Res 2002;62:3151-3158.

28. Nagata Y, Lan KH, Zhou X, Tan M, Esteva FJ, Sahin AA, Klos KS, Li P, Monia BP, Nguyen NT, Hortobagyi GN, Hung MC, Yu D. PTEN activation contributes to tumor inhibition by trastuzumab, and loss of PTEN predicts trastuzumab resistance in patients. Cancer Cell 2004;6:117-127.

29. Kono K, Takahashi A, Ichihara F, Sugai H, Fujii H, Matsumoto Y. Impaired antibody-dependent cellular cytotoxicity mediated by herceptin in patients with gastric cancer. Cancer Res 2002;62:5813-5817.

30. Tanner M, Kapanen AI, Junttila T, Raheem O, Grenman S, Elo J, Elenius K, Isola J. Characterization of a novel cell line established from a patient with Herceptinresistant breast cancer. Mol Cancer Ther 2004;3:1585-1592.

31. Nakazawa H, Yoshihara S, Kudo D, Morohashi H, Kakizaki I, Kon A, Takagaki K, Sasaki M. 4-methylumbelliferone, a hyaluronan synthase suppressor, enhances the anticancer activity of gemcitabine in human pancreatic cancer cells.

Cancer Chemother Pharmacol 2006;57:165-170.

32. Toole BP. Hyaluronan: from extracellular glue to pericellular cue. Nat Rev Cancer 2004;4:528-539.

33. Yoshihara S, Kon A, Kudo D, Nakazawa H, Kakizaki I, Sasaki M, Endo M, Takagaki K. A hyaluronan synthase suppressor, 4-methylumbelliferone, inhibits liver metastasis of melanoma cells. FEBS Lett 2005;579:2722-2726.

34. Tammi R, Ripellino JA, Margolis RU, Tammi M. Localization of epidermal hyaluronic acid using the hyaluronate binding region of cartilage proteoglycan as a specific probe. J Invest Dermatol 1988;90:412-414.

35. Gonzalez RC, Woods RE, Eddins SL. Segmentation using the watershed transform. In Digital image processing using Matlab. Pearson Prentice Hall, 2004;417-425.

36. Sebestyén Z, Nagy P, Horváth G, Vámosi G, Debets R, Gratama JW, Alexander DR, Szöllösi J. Long wavelength fluorophores and cell-by-cell correction for autofluorescence significantly improves the accuracy of flow cytometric energy transfer measurements on a dual-laser benchtop flow cytometer. Cytometry 2002;48:124-135.

37. Szentesi G, Horváth G, Bori I, Vámosi G, Szöllősi J, Gáspár R, Damjanovich S, Jenei A, Mátyus L. Computer program for determining fluorescence resonance energy transfer efficiency from flow cytometric data on a cell-by-cell basis. Computer Methods and Programs in Biomedicine 2004;75:201-211. 
38. Horváth G, Petrás M, Szentesi G, Fábián Á, Park JW, Vereb G, Szöllősi J. Selecting the right fluorophores and flow cytometer for fluorescence resonance energy transfer measurements. Cytometry A 2005;65:148-157.

39. Nagy P, Arndt-Jovin DJ, Jovin TM. Small interfering RNAs suppress the expression of endogenous and GFP-fused epidermal growth factor receptor (erbB1) and induce apoptosis in erbB1-overexpressing cells. Exp Cell Res 2003;285:39-49.

40. Szöllösi J, Trón L, Damjanovich S, Helliwell SH, Arndt Jovin D, Jovin TM. Fluorescence energy transfer measurements on cell surfaces: a critical comparison of steady-state fluorimetric and flow cytometric methods. Cytometry 1984;5:210-216.

41. Austin CD, De Maziere AM, Pisacane PI, van Dijk SM, Eigenbrot C, Sliwkowski MX, Klumperman J, Scheller RH. Endocytosis and sorting of ErbB2 and the site of action of cancer therapeutics trastuzumab and geldanamycin. Mol Biol Cell 2004;15:5268-5282.

42. Nagy P, Vereb G, Sebestyén Z, Horváth G, Lockett SJ, Damjanovich S, Park JW, Jovin TM, Szöllösi J. Lipid rafts and the local density of ErbB proteins influence the biological role of homo- and heteroassociations of ErbB2. J Cell Sci 2002;115:4251-4262.

43. Knudson W, Chow G, Knudson CB. CD44-mediated uptake and degradation of hyaluronan. Matrix Biol 2002;21:15-23.

44. Nagy P, Bene L, Balázs M, Hyun WC, Lockett SJ, Chiang NY, Waldman FM, Feuerstein BG, Damjanovich S, Szöllösi J. EGF-induced redistribution of erbB2 on breast tumor cells: Flow and image cytometric energy transfer measurements. Cytometry 1998;32:120-131.

45. Al-Hajj M, Wicha MS, Benito-Hernandez A, Morrison SJ, Clarke MF. Prospective identification of tumorigenic breast cancer cells. Proc Natl Acad Sci U S A 2003;100:3983-3988.

46. Rodriguez-Boulan E, Kreitzer G, Musch A. Organization of vesicular trafficking in epithelia. Nat Rev Mol Cell Biol 2005;6:233-247.

47. Bruno R, Washington CB, Lu JF, Lieberman G, Banken L, Klein P. Population pharmacokinetics of trastuzumab in patients with HER2+ metastatic breast cancer. Cancer Chemother Pharmacol 2005;56:361-369.

48. Toole BP, Wight TN, Tammi MI. Hyaluronan-cell interactions in cancer and vascular disease. J Biol Chem 2002;277:4593-4596.

49. Rilla K, Pasonen-Seppanen S, Rieppo J, Tammi M, Tammi R. The hyaluronan synthesis inhibitor 4-methylumbelliferone prevents keratinocyte activation and epidermal hyperproliferation induced by epidermal growth factor. $J$ Invest Dermatol 2004;123:708-714. 


\section{Figure legends:}

Figure $1 \quad$ CD44 is overexpressed in JIMT-1 cells and interacts with ErbB2

A. JIMT-1 (grey dashed line) and SKBR-3 (black dashed line) cells were labeled with AlexaFluor488-Hermes-3 antibody against CD44, and the fluorescence intensity was measured by flow cytometry. Unlabeled JIMT-1 (grey continuous line) and SKBR-3 (black continuous line) cells were used as a negative control.

B. JIMT-1 and SKBR-3 cells were labeled with Cy3-2C4 (against ErbB2) and Cy5-Hermes-3 (against CD44), and the FRET efficiency was measured by flow cytometry (black bars) and the cross-correlation coefficient by confocal microscopy (grey bars). Cells labeled with two non-competing antibodies against ErbB2 (Cy3-trastuzumab, Cy5-2C4) were used as a positive control for both FRET and cross-correlation measurements. Error bars indicate the standard error of the mean.

C. JIMT-1 cells were labeled with AlexaFluor488-2C4 and AlexaFluor647-Hermes-3 against ErbB2 and CD44, respectively. The red and green channels correspond to ErbB2 and CD44, respectively. The yellow color represents overlap between the two fluorescence channels. Quantitative evaluation of colocalization is shown in part B.

D. Left panel: JIMT-1 cell lysate was immunoprecipitated with Hermes-3 (against CD44), and the membrane was blotted with Hermes-3 and OP15 (against ErbB2). Middle and right panels: JIMT-1 cells were stimulated with $100 \mu \mathrm{g} / \mathrm{ml}$ hyaluronan decasaccharide (HA10) or large molecular weight hyaluronan (HA-LMW) for 30 min at $37{ }^{\circ} \mathrm{C}$. ErbB2 (middle panel) and ErbB1 (right panel) were immunoprecipitated with OP15 and F4, respectively. The membranes were probed with OP15, F4 and PY99 to detect ErbB2, ErbB1 and phosphotyrosine, respectively.

Figure 2 CD44 enhances trastuzumab internalization in JIMT-1 xenografts A-E. Immunofluorescent staining of JIMT-1 xenografts samples was carried out six weeks after finishing trastuzumab treatment. Sections were triple-stained with AlexaFluor488ErbB2-76.5, Cy3-anti-human IgG (recognizing trastuzumab) and AlexaFluor647-Hermes-3 (against CD44). The cell membrane identified by a manually-seeded watershed algorithm is shown in red (A). Dual color images show the correlation of signals (B: red - ErbB2, green trastuzumab; $\mathrm{C}$ : red - CD44, green - trastuzumab). Gate 1 and 2 identify regions in the trastuzumab-ErbB2 contour plot (D) corresponding to pixels with high and low trastuzumab- 
ErbB2 ratios, respectively. The CD44 intensity distributions corresponding to gate 1 and 2 are shown in part E.

F. Mice xenografted with JIMT-1 tumours were treated by trastuzumab for 15 weeks and tumour samples were stained with AlexaFluor488-ErbB2-76.5 and Cy3-anti-human IgG recognizing trastuzumab. The contour plot shows a much stronger correlation between the ErbB2 and trastuzumab signals compared to that observed in part D.

G-I. Mice injected with JIMT-1 cells were treated with saline $(\mathrm{G})$ or trastuzumab $(\mathrm{H})$ for 15 weeks. In another group mice were sacrificed 6 weeks after a 9-week long trastuzumab treatment was stopped (I), and the correlation between CD44 and ErbB2 expression levels was analyzed in the three samples.

Figure 3 siRNA-mediated suppression of CD44 expression inhibits trastuzumab internalization

A. JIMT-1 cells were transfected with an irrelevant siRNA against GFP (black), CD44 siRNA-4 (white) and CD44 siRNA-5 (grey). The bars show the expression levels of CD44 and an irrelevant protein, MHC-I, calculated from flow cytometric histograms analyzed 48 hours after transfection.

B. Internalization of trastuzumab was measured in mock-transfected cells (•), cells transfected with GFP siRNA ( $)$, CD44 siRNA-4 ( $)$ or CD44 siRNA-5 $(\diamond)$. The fraction of internalized trastuzumab $(100 \%=$ amount of trastuzumab bound to the cell surface at $0 \mathrm{~min})$ is plotted as a function of the duration of trastuzumab treatment. The 30 min values of both CD44 siRNA-transfected samples were statistically significantly different from the GFP siRNA-transfected one (Student's $t$ test, $p<0.05$ ). Error bars indicate the standard error of the mean.

Figure 4 4-methylumbelliferone acts synergistically with trastuzumab in inhibiting tumour growth and down-regulating ErbB2 expression

A. Mice were xenografted with JIMT-1 cells, and treated with saline (•), trastuzumab (०), 4methylumbelliferone $(\boldsymbol{\nabla})$ or trastuzumab+4-methylumbelliferone $(\diamond)$. 4-methylumbelliferone treatment was carried out daily. At the times of weekly saline and trastuzumab treatments indicated by the arrows the size of tumours was measured, and it is displayed as function of time.

B. Tissue sections were triple-labeled with biotin-HABC and fluorescein-avidin to visualize hyaluronan, and antibodies against CD44 and ErbB2. The cell membrane of JIMT-1 cells was 
identified by the manually-seeded watershed algorithm. The mean ( \pm standard error of the mean) expression levels of hyaluronan, CD44 and ErbB2 measured around the cell membrane in trastuzumab (white), 4-methylumbelliferone (left-hatched) and trastuzumab+4methylumbelliferone (grey) treated animals were normalized to the saline-treated xenograft samples (black). The means were calculated from 6 images taken of tissue sections of 3 animals.

Figure 5 Inhibition of hyaluronan synthase increases binding of trastuzumab to ErbB2 A-C. JIMT-1 tumour samples of saline-treated animals were stained for hyaluronan with biotin-HABC (A) and for CD44 (B). The color composite image shows the overlap of the distribution of the hyaluronan (green) and CD44 (red) signals.

D-F. Tumour sections of mice treated with trastuzumab (D) or trastuzumab+4methylumbelliferone (E) were stained with anti-human IgG (recognizing trastuzumab, green) and ErbB2-76.5 (red) antibodies. The contour plot (F) shows increased binding of trastuzumab to ErbB2 in samples taken from the trastuzumab+4-methylumbelliferone-treated animals (red contours) compared to the trastuzumab-treated ones (black contours). The axes of the contour plot show fluorescence intensity values of trastuzumab and ErbB2-76.5 antibodies recorded in membrane pixels which were identified by manually-seeded watershed segmentation.

G. Cultured JIMT-1 cells were treated with 4-methylumbelliferone for 2 days. Both control (black contours) and 4-methylumbelliferone-treated (red contours) cells were stained with AlexaFluor488-trastuzumab and AlexaFluor647-2C4. The latter antibody measured the amount of ErbB2.

Figure 6 RNA interference-mediated suppression of CD44 expression inhibits proliferation of JIMT-1 cells

An equal number of mock-transfected cells (white bars) and cells transfected with GFP siRNA (black bars) or CD44 siRNA-4 (grey bars) were seeded into 6-well plates 24 hours after transfection, and cultured in the absence (-trast) or presence (+trast) of $20 \mu \mathrm{g} / \mathrm{ml}$ trastuzumab for 72 hours. Cell numbers are normalized to the number found in mocktransfected, trastuzumab-untreated cells 72 hours after transfection. 


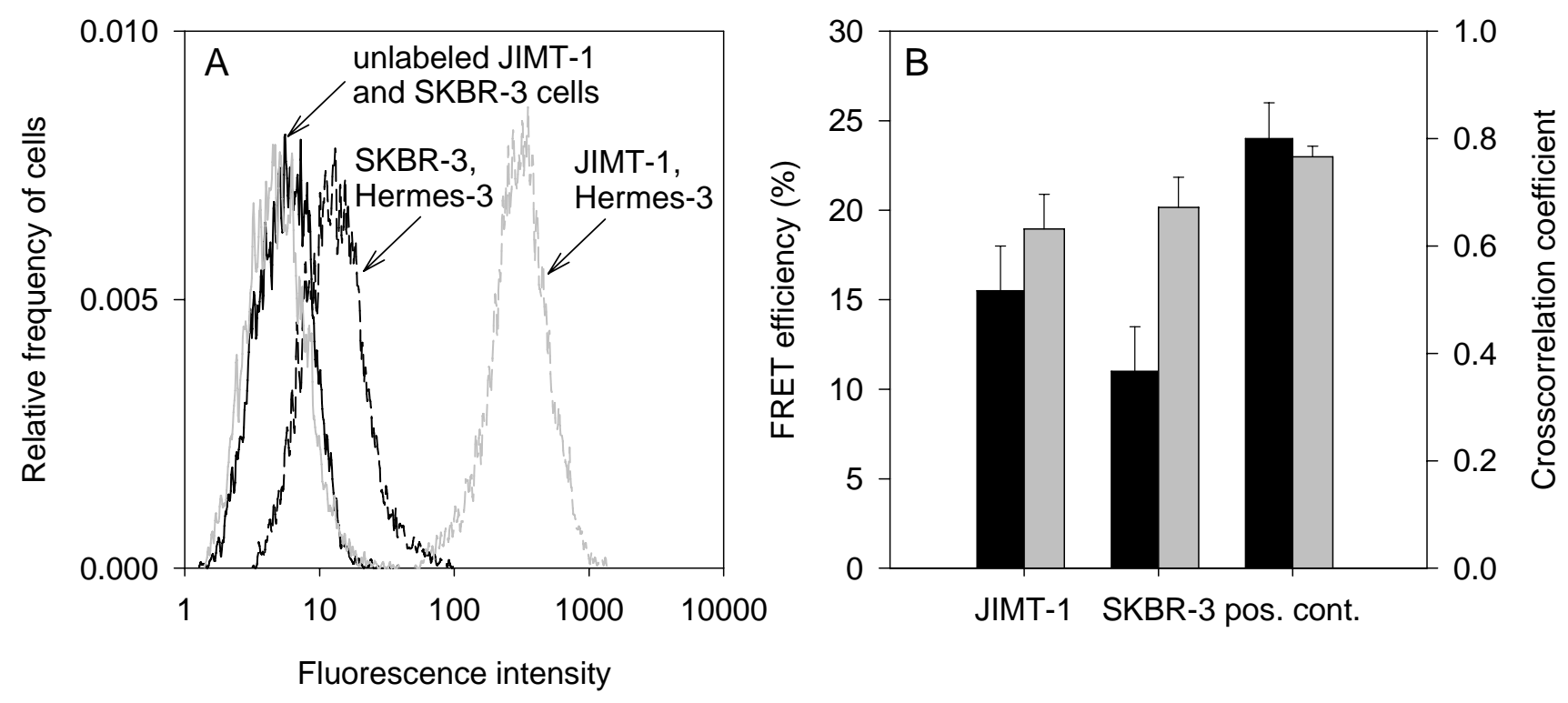

Fig. 1

Pályi-Krekk et al. 


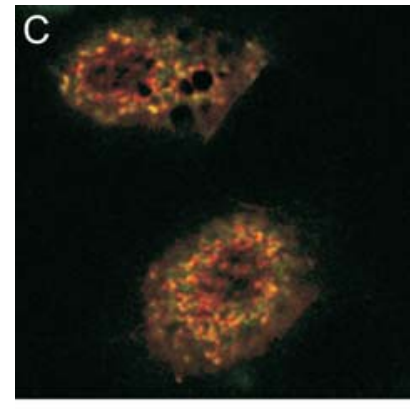

Fig. 1

Pályi-Krekk et al. 
HA10 - + HA10 - -+

HA-LMW $-+-\quad$ HA-LMW -+-

WB: OP15 - WB: PY99 - - W W: PY99

WB: Hermes-3 - WB: OP15

IP: Hermes-3 IP: OP15 IP: F4

Fig. 1D

Pályi-Krekk et al. 


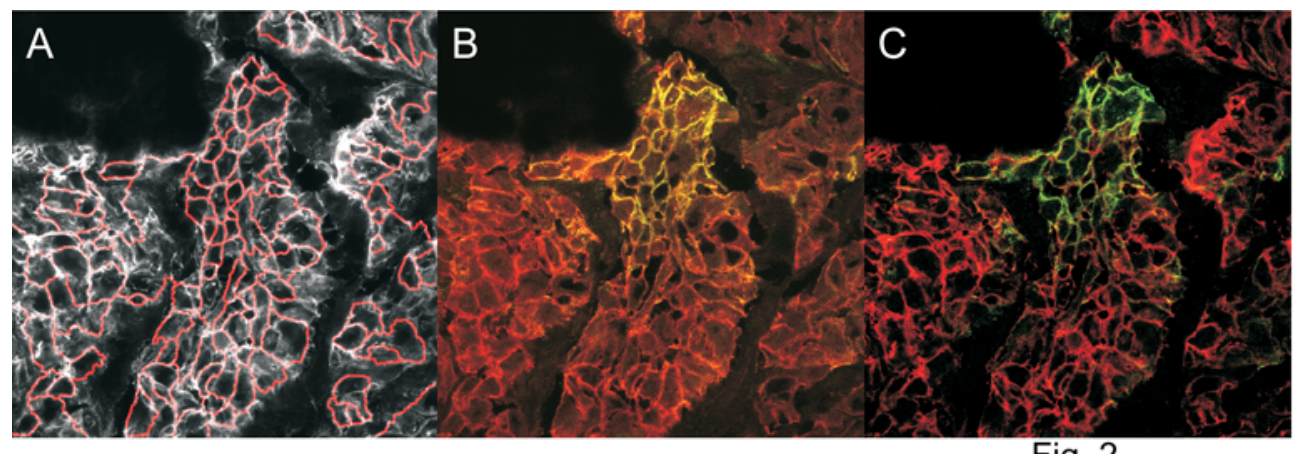

Pălyi-Krekk et al. 

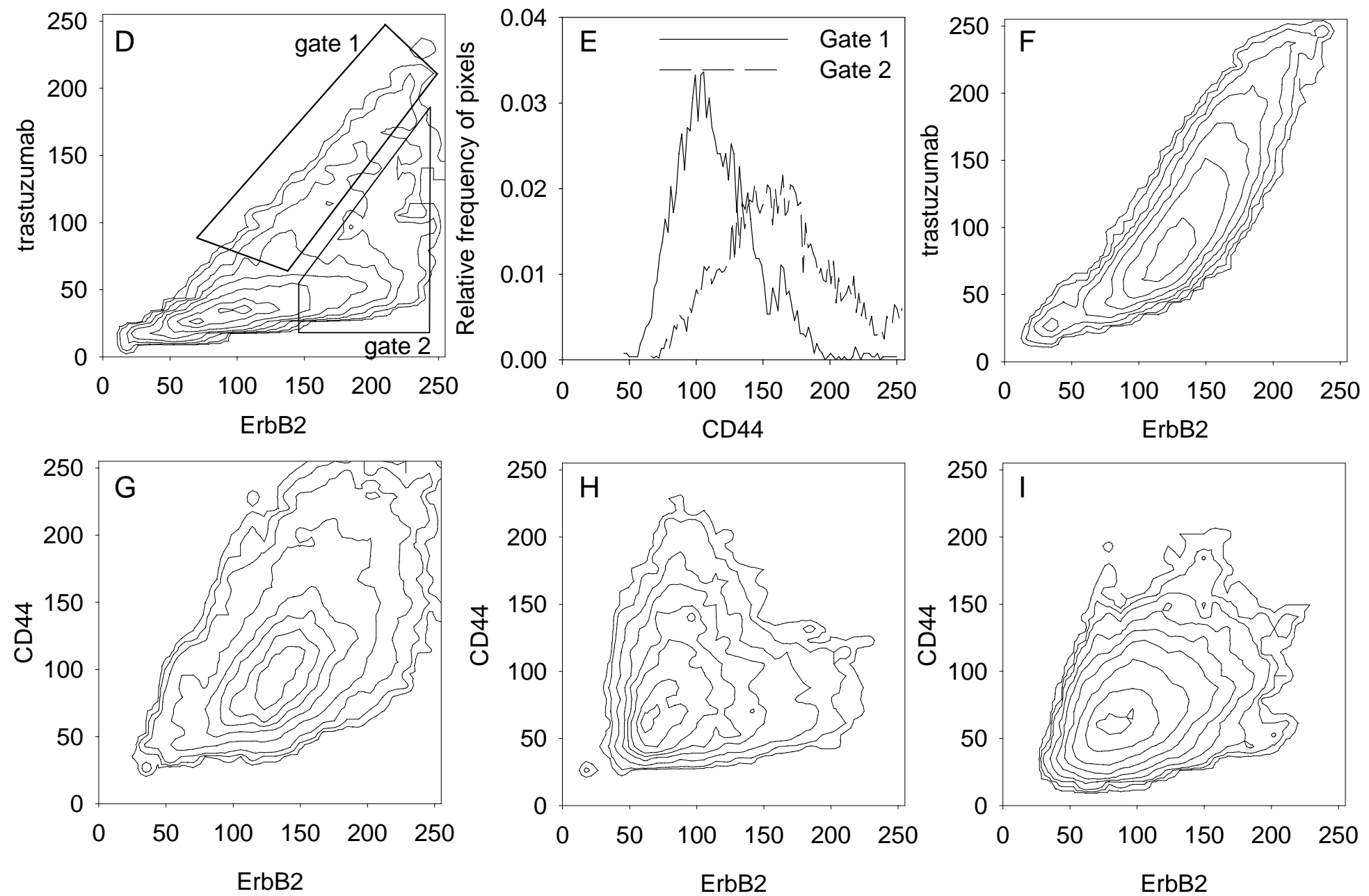

Fig. 2D-I

Pályi-Krekk et al. 

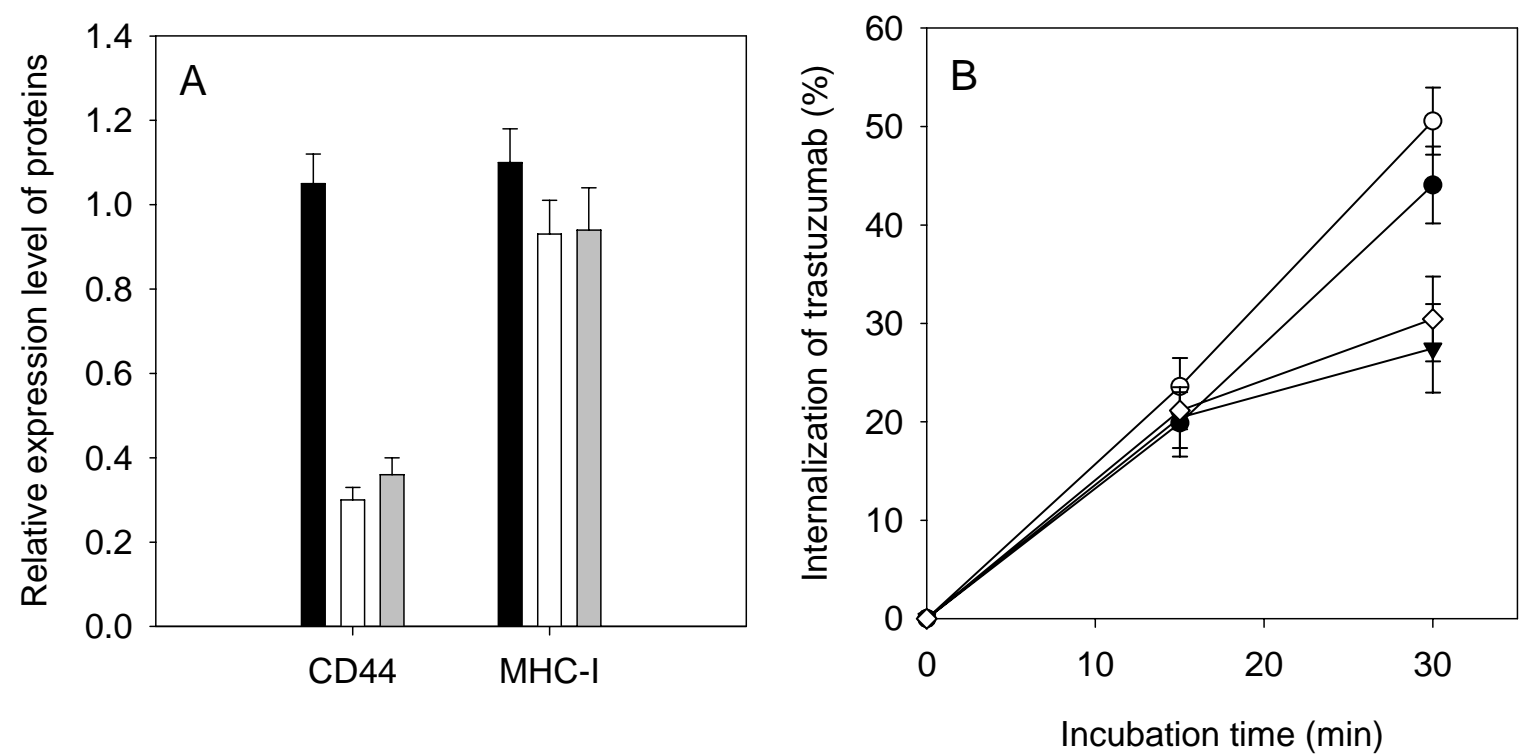

Fig. 3

Pályi-Krekk et al. 

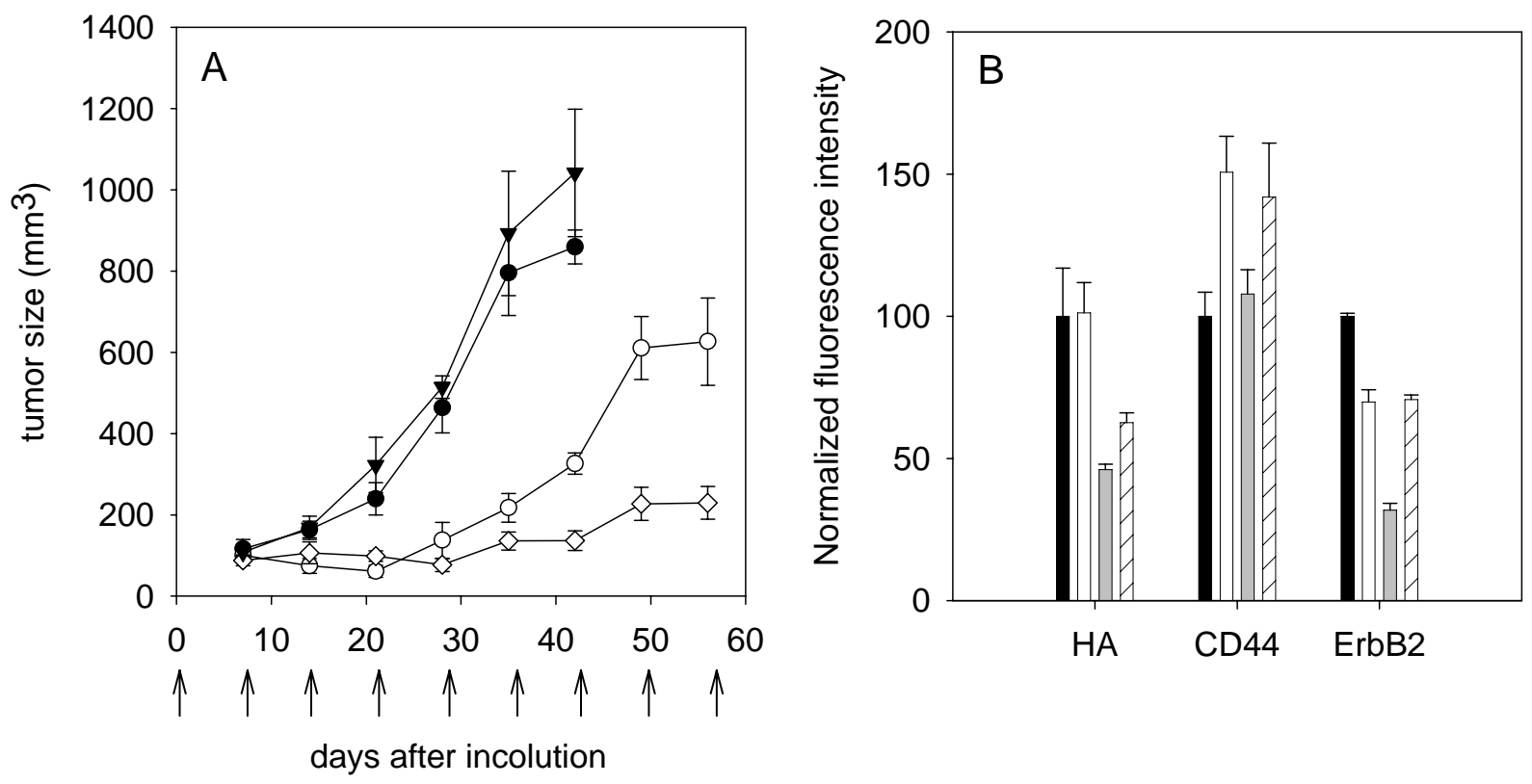

Fig. 4

Pályi-Krekk et al. 

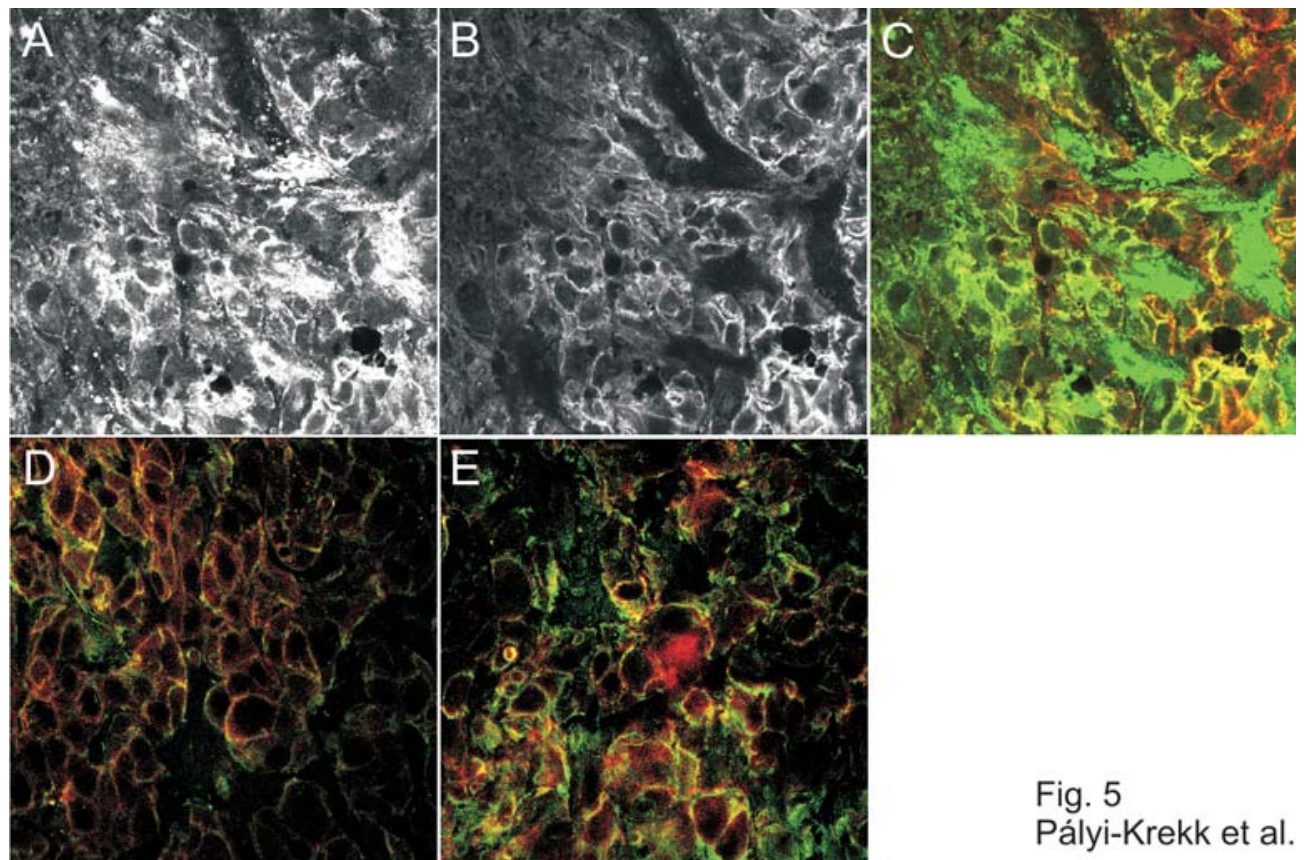

Fig. 5

Pályi-Krekk et al. 

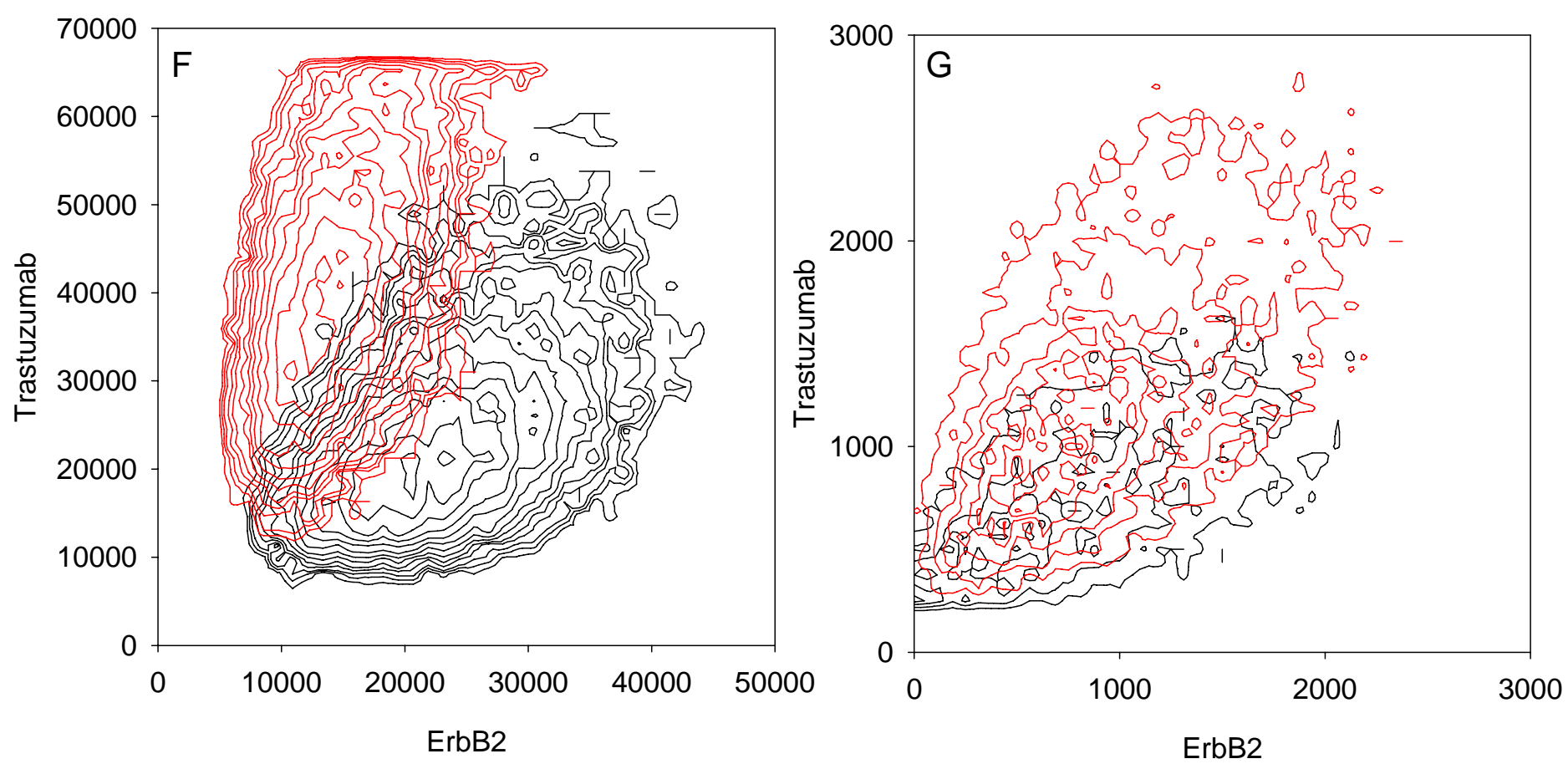

Fig. 5F-G

Pályi-Krekk et al. 


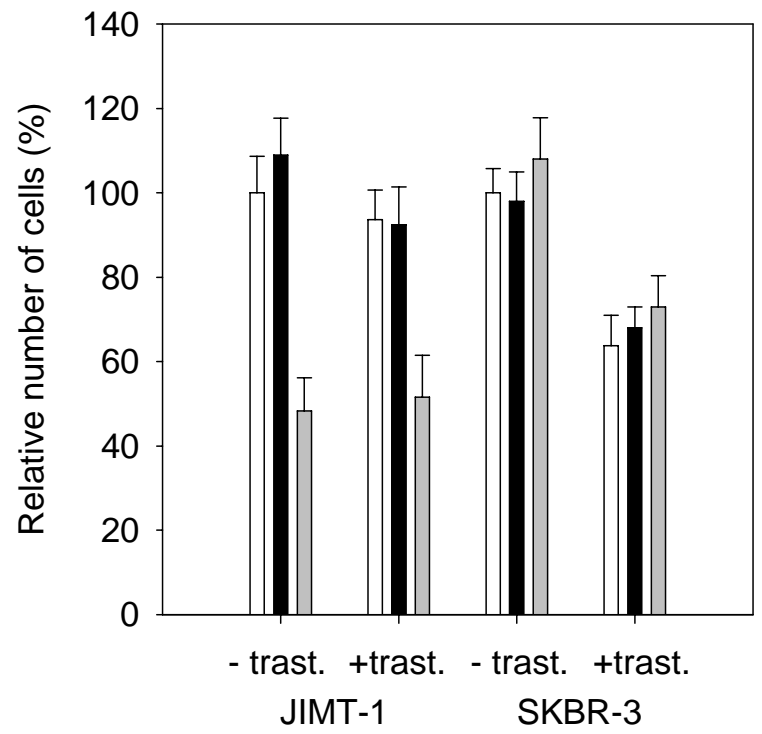

Fig. 6

Pályi-Krekk et al. 